\title{
Alcohol Use Disorder Interventions Targeting Brain Sites for Both Conditioned Reward and Delayed Gratification
}

\author{
Brandon G. Oberlin ${ }^{1,2,3,4}$ (D) Y Yitong I. Shen ${ }^{1,2}$. David A. Kareken ${ }^{1,2,4}$ \\ Published online: 20 December 2019 \\ (C) The American Society for Experimental NeuroTherapeutics, Inc. 2019
}

\begin{abstract}
Alcohol use disorder is a destructive compulsion characterized by chronic relapse and poor recovery outcomes. Heightened reactivity to alcohol-associated stimuli and compromised executive function are hallmarks of alcohol use disorder. Interventions targeting these two interacting domains are thought to ameliorate these altered states, but the mutual brain sites of action are yet unknown. Although interventions on alcohol cue reactivity affect reward area responses, how treatments alter brain responses when subjects exert executive effort to delay gratification is not as well-characterized. Focusing on interventions that could be developed into effective clinical treatments, we review and identify brain sites of action for these two categories of potential therapies. Using activation likelihood estimation (ALE) meta-analysis, we find that interventions on alcohol cue reactivity localize to ventral prefrontal cortex, dorsal anterior cingulate, and temporal, striatal, and thalamic regions. Interventions for increasing delayed reward preference elicit changes mostly in midline default mode network regions, including posterior cingulate, precuneus, and ventromedial prefrontal cortex - in addition to temporal and parietal regions. Anatomical co-localization of effects appears in the ventromedial prefrontal cortex, whereas effects specific to delay-of-gratification appear in the posterior cingulate and precuneus. Thus, the current available literature suggests that interventions in the domains of cue reactivity and delay discounting alter brain activity along midline default mode regions, specifically in the ventromedial prefrontal cortex for both domains, and the posterior cingulate/precuneus for delay-of-gratification. We believe that these findings could facilitate targeting and development of new interventions, and ultimately treatments of this challenging disorder.
\end{abstract}

Keywords Meta analysis $\cdot$ impulsivity $\cdot$ intertemporal choice $\cdot$ addiction $\cdot$ cues $\cdot$ ethanol $\cdot$ alcoholism

\section{Introduction}

A range of modern interventions show promise for facilitating alcohol use disorder (AUD) treatment, including pharmacotherapies (acting at opioid, glutamate, GABA, 5HT, and

Brandon G. Oberlin

boberlin@iupui.edu

1 Department of Psychiatry, Indiana University School of Medicine, Indianapolis, USA

2 Department of Neurology, Indiana University School of Medicine, Indianapolis,, USA

3 Addiction Neuroscience Program, Department of Psychology, Indiana University Purdue University at Indianapolis, School of Science, Indianapolis, USA

4 Stark Neurosciences Research Institute, Indiana University School of Medicine, Indianapolis, USA acetylcholine receptors) and behavioral-psychological interventions (e.g., brief interventions, motivational interviewing, contingency management, cognitive behavioral therapy, mindfulness-based approaches, and computerized, mobile, and web-based methods); for recent reviews, see [1,2]. Although the newest methods await further testing, contemporary modern techniques will still require considerable improvement to achieve high efficacy for long-term relapse prevention. A sizable portion of AUD patients still return to drinking within 6 months post-treatment, with disappointing progress on efficacy over the past 40 years [3-6]. The critical need for effective treatments has driven the creative development of a range of interventions. Identifying common brain areas sensitive to such interventions could facilitate refining these treatments, lead to innovative new treatments, and provide better spatial targeting for neuromodulatory manipulations (e.g., as required for transcranial magnetic stimulation; TMS). The present review is aimed at identifying potential brain targets for therapeutic interventions in AUD. 
A key element of AUD is a biased preference toward highly salient alcohol rewards and away from more abstract rewards such as human relationships, health, and career opportunities [7]. Therefore, promising treatments should act to reverse these tendencies. Recent neurofunctional domain-based nosology identifies three key domains of AUD and other addictions: incentive salience, executive function, and negative emotionality $[8,9]$. Insofar as targeting two interrelated domains should increase the therapeutic potential of any putative interventions, we review the nature of brain systems governing i) the power of conditioned cues to motivate behavior, ii) the ability of these cues to distort executive function (influence decision-making), and iii) myopic reward decisionmaking. We limit the scope of the present review to the two domains - incentive salience and executive function - most implicated in positive reinforcement-related AUD. These two domains are especially implicated in positive reinforcement-related AUD subtypes, e.g., high noveltyseeking and impulsivity subtypes such as the previously defined type II (early-onset, familial alcoholism, high noveltyseeking, low harm avoidance; [10]), type B (early-onset, familial alcoholism, polydrug use, greater psychopathology; [11]), or "reward drinking" phenotype [12-14], predicting poorer recovery outcomes [15]. Further, these domains interact in brain regions key to reward decision-making, as recently demonstrated in PCC/precuneus of heavy drinkers with alcohol taste cues and delay discounting [16]. Using spatial metaanalytic techniques, we report brain regions responding to interventions on cue reactivity and delay-of-gratification, representing the incentive salience and executive function domains, respectively.

\section{Incentive Salience: Cue Reactivity}

Through Pavlovian learning and the repeated pairing of intoxication with alcohol's associated sensory stimuli, alcohol's conditioned cues acquire the capacity to alter motivational systems in the brain (particularly in mesostriatal dopamine systems). As a result, such learning can create lasting changes that induce "wanting" and invigorate seeking behavior (for reviews, see [17, 18]). Alcohol-associated cues can thus increase drinking [19, 20], elicit physiological responses in AUD that predict later drinking frequency [21], and provoke greater skin conductance and craving in AUD versus healthy controls [22].

Brain responses are a special class of conditioned responses insofar as they are in a position to modulate decision-making and behavioral action. The dominant method for studying this in humans is fMRI, which is but a hemodynamic proxy for neuronal activation. Nonetheless, there is evidence from positron emission tomography that alcohol-associated sensory stimuli do promote striatal dopamine transmission in humans and that the fMRI response in the striatum at least partially reflects this [23-25]. More broadly, alcohol cue-activated brain reward systems predict drinking [26] and relapse [27], and differentiate subjects who transition to heavy drinking [28]. Cue-induced brain activity also correlates with AUD severity [29] and reflects abstinence [30]. Therefore, any successful treatment for AUD might be expected to alter cueelicited responses, particularly attenuating reward-linked limbic responses, and/or enhancing executive regions [31]. The extant literature thus indicates that neuroimaging of cue reactivity is a promising index of treatment efficacy in the incentive salience domain.

\section{Executive Function: Delay-of-Gratification}

Evocation of the brain's motivational system is, however, but one aspect of a larger behavioral ensemble. Adaptive behavior in the environment requires that the urges elicited by alcohol's (and other reward's) cues be appropriately restrained and regulated. Impaired regulatory capacity may reflect one aspect of an inherited predisposition to AUD, which entails an altered set of executive abilities (e.g., 32, 33-35), in addition to any impairment induced by alcohol itself ( 36 for review). While tempting to regard AUD as largely a function of alcohol reward-i.e., that alcohol's elevated appetitive value in some people drives compulsive use - one key observation highlights the primary role of adaptive executive regulation: the majority of Americans derive reward from alcohol (71\% pastyear drinking), but only a small fraction engage in pathological use (6\% AUD; 37). Considerable work implicates impaired delay-of-gratification in AUD [38-44] and other addictions. Beyond alcohol, this tendency scales with addiction severity across a range of substances and risk measures (for meta-analysis, see 45), suggesting a phenotypic marker for addiction [46]. Delay discounting tasks simultaneously measure immediacy preference and delay aversion, which together with drug over-valuation, represent a high-risk phenotype [47]. Discounting robustly predicts post-treatment smoking relapse [48], and treatment response [49-52], and thus offers a potentially viable therapeutic target [53]. Given the clinical importance of behavioral discounting processes to AUD and recovery, we extend the work of several comprehensive metaanalyses of brain regions associated with delay discounting [54-57] by focusing specifically on interventions targeting delay-of-gratification.

\section{Rationale}

With increasing interventions for AUD and other substance use disorders that are designed to target specific brain loci [58], and the concomitant need for spatial targets, we endeavored to map brain locations most likely to respond to interventions targeting cue reactivity and delay discounting, given their importance in addiction processes and recovery. 


\section{Objectives}

We used spatial meta-analytic techniques for fMRI to examine studies employing manipulations designed to attenuate alcohol cue reactivity and delay discounting in a range of drinkers, from healthy controls to heavy drinkers. Both pharmacological and behavioral interventions were employed in both domains. We prioritized manipulations designed to effect longterm change, and so selected studies using pre- versus postintervention designs with stringent inclusion criteria, assuming that these represented manipulations with potentially lasting efficacy, and therefore clinical utility. Unfortunately, the nascent field of enhancing delay-of-gratification does not yet contain pre- versus post-intervention studies; therefore, we opted to include acute manipulations of discounting as a first-pass assessment of brain regions likely to be involved in this critical executive process. Although the methods and samples of the reviewed manuscripts differ in important ways, we will conduct these analyses in parallel, and compare the independent results for convergence and divergence of these anatomic systems supporting related domains. Our outcome of interest, in all cases, was a change in brain activation corresponding to the manipulation, specifically within-subject or group interactions in altered brain activity. Our present review of findings from interventions that change activation is therefore designed to identify brain regions jointly sensitive to manipulations of conditioned alcohol reward and increased delay-of-gratification.

\section{Methods}

We report this review in accordance with the PRISMA (Preferred Reporting Items for Systematic Reviews and Meta-Analyses) guidelines ${ }^{1}$ [59], although note that the lack of fMRI variability estimates precluded heterogeneity estimates.

\section{Eligibility Criteria}

To be considered for inclusion, studies had to meet the following criteria: 1) performed an intervention targeting conditioned alcohol reward or monetary delay discounting; 2) used human laboratory paradigms with alcohol cue exposure or delay discounting during fMRI; 3) reported pre- versus postintervention fMRI results in within-subjects or mixed designs, i.e., studies using a single session intervention were excluded: studies using single session interventions on delay discounting were included; 4) reported whole-brain general linear modelbased voxel-wise fMRI results in standardized space (only the whole-brain results were used in studies reporting both whole-

\footnotetext{
${ }^{1}$ We did not upload a finalized review protocol to a public database a priori.
}

brain and a priori region of interest [ROI]-based analyses); 5) published in a peer-reviewed English language journal. The intent was to identify brain locations responding after an intervention, i.e., pre- versus post-intervention for both cue reactivity and delay discounting; however, an initial search revealed that the published delay discounting fMRI intervention studies used within-session experimental manipulations only (except [60]). Although imperfectly matched, these comparisons should inform spatial activation patterns for both classes of interventions.

\section{Sources, Searches, and Study Selection}

Our primary database searches were conducted in PubMed (https://www.ncbi.nlm.nih.gov/pubmed/), with secondary searches of Google Scholar (https://scholar.google.com/), and follow-up from references listed in relevant reviews.

We conducted literature searches (up to August 29, 2019) and identified potential studies with the following two-step procedure. For cue reactivity studies: 1) PubMed searches of the title/abstract using the following search terms: "fMRI" AND "cue reactivity" AND "alcohol"; "imaging" AND "cue reactivity" AND "alcohol"; "training" AND "alcohol cues" AND "alcohol dependent"; "cues" AND "reduced" AND "alcohol" AND "fMRI"; 2) on Google Scholar searching within the whole article using the following search terms: "MRI", "alcohol dependent" OR "alcohol use disorder", "alcohol cue reactivity." The delay discounting papers were identified with 1) PubMed searches of the title/abstract using the following search terms: "discounting" AND "intervention" AND "fMRI"; "delay discounting" AND "clinical trial"; "reduces" AND "delay discounting" AND "fMRI"; "fMRI" AND "intertemporal" AND "episodic"; "intertemporal choice" AND "future rewards" OR "later rewards" AND "imaging" AND "task" AND "decision"; 2) on Google Scholar searching within the whole article using the following search terms: "delay discounting," "reduce," "decision," "treatment," "fMRI," "comparison," "pre," "post," "coordinates." These papers were carefully screened, and all suitable papers were subjected to reverse lookup ("cited by") on Google Scholar to identify additional papers. Relevant reviews and meta-analyses were consulted to ensure complete inclusion. One author (YIS) conducted both full literature searches, with two authors (BGO and YIS) reviewing all final records for inclusion. Records raising questions for inclusion required consensus to finalize. Data extraction and entry was independently verified by two authors.

\section{Data Collection and Summary Measures}

Activation peak coordinates resulting from the intervention were the outcomes of interest and were collected from published tables. In all but one study, $Z, t$, or $F$ statistics were 
reported for the corresponding peaks; these were used to calculate Cohen's $d$. One effect size was estimated [61] for the study that did not report it [60].

\section{fMRI Outcomes: Activation Likelihood Estimation}

Coordinate-based meta-analysis permits estimating the likelihood of a region's involvement in a particular phenomenon and increases the generalizability of findings from diverse neuroimaging studies. ALE models activation peaks from multiple studies as spatial probability distributions in the whole brain - permitting random effects inference to the study populations. We performed ALE analyses with GingerALE [62] v3.0.2 (http://brainmap.org/ale/) in MNI space, with a threshold of $p_{\text {uncorr }}<0.001$, and extent of $100 \mathrm{~mm}^{3}$. We relied on ALE primarily to identify the loci of peak spatial convergence, but we additionally performed permutationbased cluster correction. Although we recognize that there is an insufficient number of published studies meeting our selection criteria for a well-powered activation likelihood estimation (ALE) meta-analysis [62, 63], we present findings from a range of intervention studies and use ALE to estimate the centroids of the results reported. Coordinates originally reported in Talairach space were transformed to MNI prior to ALE.

\section{Risk of Bias}

The presence of publication bias was assessed separately for cue reactivity and delay discounting with the visual detection of asymmetry in funnel plots (study $n$ s against effect sizes). Cohen's $d$ effect sizes were calculated from published $Z$ or $t$ statistics using the highest activation peak statistic in each study, representing the greatest potential for bias (e.g., 64). Right-skewed plots indicate the possibility of publication bias favoring significant results, particularly with smaller sample sizes. This was followed by Orwin's fail-safe $\mathrm{N}$ analysis [65] to determine the number of missing studies with null results required to reduce the study sample mean to a small effect size $(d \leq 0.2 ;[66])$. Given that the outcomes of interest are activation peaks from fMRI analyses, the threats to individual study bias exist largely in fMRI thresholding and analyses, which is discussed in narrative form.

\section{Results}

\section{Study Characteristics and Subjects}

The study identification and screening flow chart is shown in Fig. 1. The searches returned 472 results for cue reactivity, and 233 results for delay discounting in total from both PubMed and Google Scholar. Reasons for exclusion included no relevant sample, review paper, not an fMRI study, no pre-/ postintervention comparison for cue reactivity, and no targeted intervention for delay discounting. Other exclusions listed in Fig. 1 are 1) not reporting significant peaks in the pre/ post alcohol-neutral contrast and thus therefore unusable for ALE [67], and 2) presented results obtained during operant behavior rather than simple cue reactivity [68]. After filtering all potential studies for our inclusion criteria, the literature search yielded a total of 10 studies (284 subjects and 87 foci) for cue reactivity and 9 studies (206 subjects and 81 foci) for delay discounting; details are summarized in Tables 1 and 2, respectively. Note that one study [69] using neurofeedback in a single session was included among the cue reactivity studies, as they measured activation outcomes pre-/postintervention in a first versus last scan analysis. Note that a subset of $n=13$ in one study [70] received a separate intervention and fMRI in addition to the main results in $n=23$, so the peaks for those were separately included in ALE as $n=13$. Studies reporting only functional connectivity results were not included (e.g., [71]), as these cannot be used in ALE analyses.

Cue reactivity studies tested currently drinking or abstinent AUD subjects or heavy drinkers (HD), with all subjects sober during fMRI. Subjects were characterized as AUD by DSMIV, ICD-10, or the Mini International Neuropsychiatric Interview. HD were defined by AUDIT scores above 8 or exceeding 2 heavy drinking days per week, and $\geq 21$ or 14 drinks per week for men or women, respectively. Our interest in intervention effects precluded studies evaluating the effects of abstinence alone (e.g., [72]). Just one cue reactivity study included control subjects. Most of the delay discounting studies used only healthy subjects, except one using abstinent AUD [60], and another with pathological gamblers [73]. One delay discounting intervention study otherwise meeting criteria was excluded due to likely nonspecific brain deficits in pre-dementia patients [74]. Finally, these analyses did not require protection of human subjects review, as all data were previously published and contained no confidential information.

\section{Paradigms, Stimuli, and Interventions}

All the cue reactivity paradigms used images of alcohol drinks (one with additional olfactory cues) designed to elicit alcoholassociated conditioned reward, and control images of either non-alcohol drinks or a visually matched abstract image, some from the International Affective Picture database [75]. Interventions used on cue reactivity spanned a wide range, including putative pharmacotherapies, magnetic or direct current stimulation, behavioral extinction training, or neurofeedback training. Interventions were performed after the first fMRI scan (except the neurofeedback study, which was concurrent to scanning) and were assessed for effects on cue reactivity by within-subjects comparisons to the postscan. 
Fig. 1 Study selection and inclusion

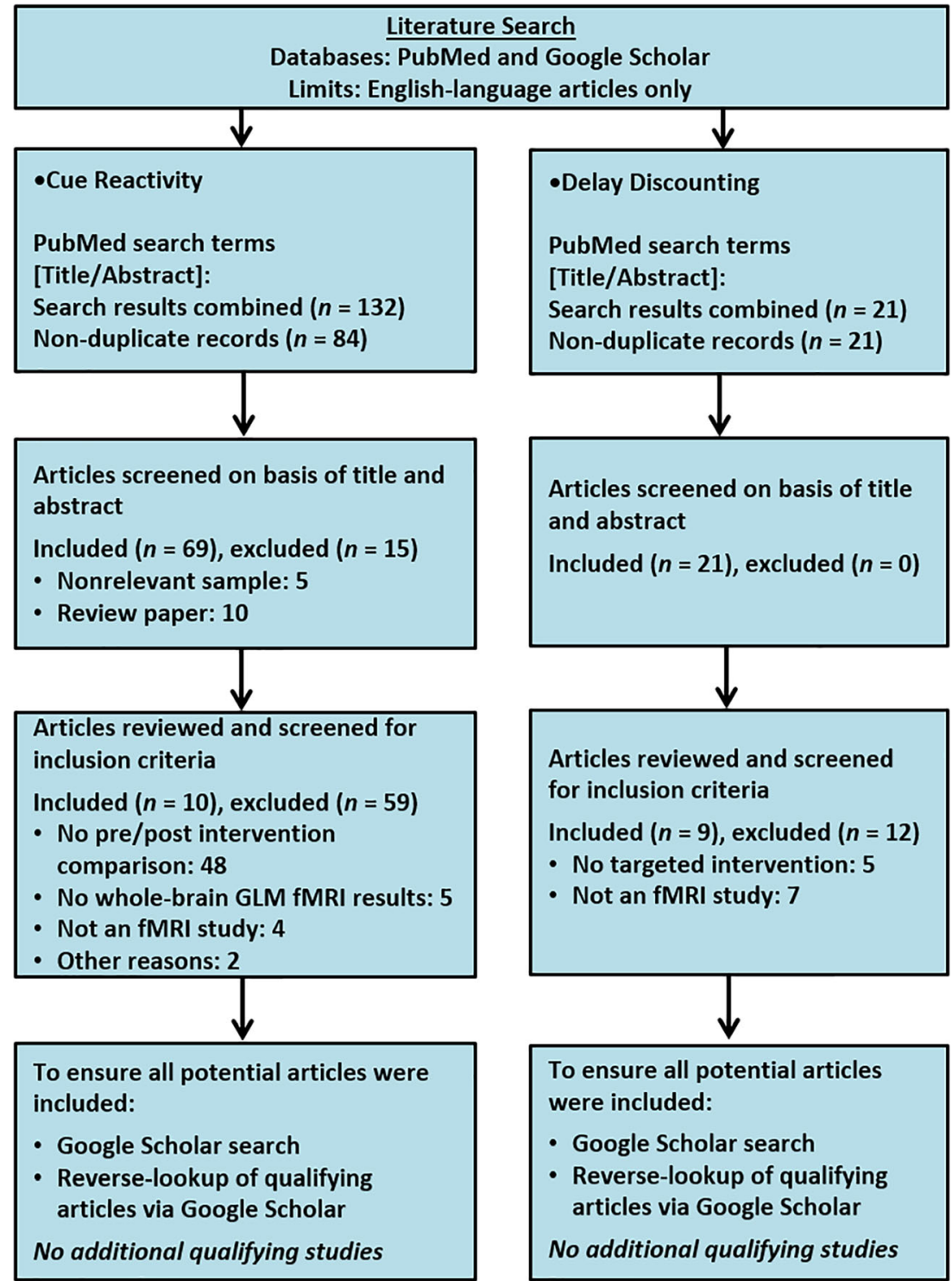

The delay discounting paradigms used similar binary choice paradigms comprising a choice between a smaller/ sooner (e.g., "now") or a larger/later delayed monetary reward. All non-pharmacological interventions presented stimuli that were designed to increase preference for the delayed reward - these were displayed during, or just preceding, the choice period during monetary delay discounting in fMRI. The majority of the DD intervention studies (6 out of 9) employed versions of episodic future thinking (EFT). By invoking a personalized, relevant future, EFT cues are intended to increase preference for future rewards by eliciting brain activation related to the abstract valuation of a future event. The EFT studies reported here used extensive pre-scan interviews to identify specific events relevant for each subject that were planned for the near future (e.g., "vacation paris," "friend's wedding," "mum's birthday"; [76]). These were later presented during fMRI as text inserted into the delay discounting paradigm immediately preceding choice. The episodic trials were compared with visually similar control trials with placeholder strings. Other EFT variations used an "Imagine" (spending the money) versus an "Estimate" (what the money could buy) condition [77] or episodic future café meetings [78, 79]. Non-EFT interventions used images of emotional faces versus neutral faces [80] or naltrexone versus placebo [60]. Although some interventions, such as emotional faces, would not likely form the basis of an AUD treatment (but see "Discussion"), our interest was in discovering brain regions sensitive to manipulations of DD by various methods.

\section{Interventions on Cue Reactivity: fMRI}

Convergent brain regions showing intervention effects on alcohol cue reactivity were localized mostly to the left hemisphere and included the left dorsal caudate, 
Table 1 Alcohol cue reactivity intervention studies

\begin{tabular}{|c|c|c|c|c|c|c|c|c|}
\hline First author & Year & $\mathrm{N}^{1}$ & Age $\pm \mathrm{SD}$ & $\begin{array}{l}\% \\
\text { male }\end{array}$ & Cue type ${ }^{2}$ & Intervention & Design & WB threshold ${ }^{3}$ \\
\hline Hermann & 2006 & $\begin{array}{l}10 \mathrm{AA}, \\
10 \mathrm{HC}\end{array}$ & $39^{\mathrm{b}}$ & 100 & Visual & $400 \mathrm{mg}$ amisulpride & Amisulpride $<$ no medication & $p_{\text {uncorr }}<0.001$ \\
\hline Vollstädt-Klein & 2011 & $30 \mathrm{AA}$ & $46.5^{\mathrm{b}}$ & 63 & Visual & CET & Pre $>$ post-treatment & $p_{\text {uncorr }}<0.001$ \\
\hline Lukas & 2013 & $28 \mathrm{AA}$ & $48.36^{\mathrm{b}}$ & 75 & $\begin{array}{l}\text { Visual and } \\
\text { olfactory }\end{array}$ & 380 mg XR-NTX & Pre-post, XR-NTX > placebo & $p_{F W E}<0.05$ \\
\hline Herremans & 2015 & $23 \mathrm{AA}^{\mathrm{a}}$ & $45.2 \pm 9.3^{\mathrm{c}}$ & 65 & Visual & Active HF-rTMS & Pre $>$ post-treatment ${ }^{\mathrm{a}}$ & $p_{\text {corr }}<0.005$ \\
\hline Kiefer & 2015 & $32 \mathrm{DT}$ & $44.94 \pm 9.54$ & 65.5 & Visual & $\mathrm{CET}^{\mathrm{d}}$ & Pre $>$ post-treatment & $p_{\text {uncorr }}<0.001$ \\
\hline Wiers & 2015 & $32 \mathrm{AA}$ & $43.93^{\mathrm{b}}$ & 100 & Visual & Bias Modification & $\begin{array}{l}\text { Pre-post, bias modification } \\
\quad>\text { sham }\end{array}$ & $p_{\text {uncorr }}<0.005$ \\
\hline Kirsch & 2016 & $38 \mathrm{HD}$ & 24.11 & 76 & Visual & rtfMRI NF & $\mathrm{rFB}>$ control & $p_{\text {corr }}<0.005$ \\
\hline Beck & 2018 & $23 \mathrm{AA}$ & $46.17 \pm 6.15$ & 70 & Visual & $\begin{array}{l}138 \mathrm{mg} / \text { day } \\
\text { baclofen }^{\text {e }}\end{array}$ & $\begin{array}{l}\text { Baclofen pre }>\text { post versus } \\
\text { placebo pre }>\text { post }\end{array}$ & $p_{\text {uncorr }}<0.001$ \\
\hline Holla & 2018 & $33 \mathrm{TS}$ & $36.23^{\mathrm{b}, \mathrm{c}}$ & 100 & Visual & $\begin{array}{l}57.6 \mathrm{mg} / \text { day } \\
\text { baclofen }^{\mathrm{e}}\end{array}$ & $\begin{array}{l}\text { Interaction treatment } \times \text { time } \\
\quad(\text { baclofen }- \text { control })\end{array}$ & $\begin{array}{l}p_{\text {uncorr }}<0.001, \\
\quad k=53^{\mathrm{d}}\end{array}$ \\
\hline Bach & 2019 & $35 \mathrm{AA}$ & $45.85^{\mathrm{b}}$ & 100 & Visual & $I W T+N_{T X}^{f}$ & $\begin{array}{l}\text { Interaction treatment } x \text { time } \\
(\text { IWT }+ \text { NTX }>\text { IWT })\end{array}$ & $\begin{array}{c}p_{\text {uncorr }}<0.001, \\
k=33^{\mathrm{g}}\end{array}$ \\
\hline
\end{tabular}

$\mathrm{AA}=$ abstinent alcohol-dependent $\mathrm{HC}=$ healthy; $\mathrm{DT}=$ detoxified $\mathrm{HD}=$ heavy drinking; $\mathrm{TS}=$ treatment seeking alcohol-dependent; $\mathrm{XR}-\mathrm{NTX}=$ oncemonthly extended-release Naltrexone; CET = cue-exposure based extinction training; DCS = D-cycloserine; rtfMRI NF = real-time fMRI neurofeedback; $\mathrm{rFB}$ = real feedback; HF-rTMS = high-frequency repetitive transcranial magnetic stimulation; IWT = intensive withdrawal treatment; NTX = naltrexone

${ }^{1}$ Including only subjects with useable fMRI data $;{ }^{2}$ used in-scanner; ${ }^{3} \mathrm{WB}=$ whole brain (Subscripts indicate correction: corr $=$ corrected, $\mathrm{FWE}=$ familywise error corrected, uncorr $=$ uncorrected, $\mathrm{CC}=$ cluster corrected)

${ }^{a} 13$ of these 23 underwent a separate intervention with a single active session and were therefore analyzed as an additional study

${ }^{\mathrm{b}}$ Calculated as weighted means, SD not reported; ${ }^{\mathrm{c}}$ provided only for initial group before drop out/exclusion; ${ }^{\mathrm{d}} N=16$ received $50 \mathrm{mg} \mathrm{D}$-cycloserine and $N=16$ received placebo prior to CET treatments; ${ }^{\mathrm{e}}$ mean dose; ${ }^{\mathrm{f}}$ dose not given; ${ }^{\mathrm{g}}$ Monte Carlo simulations to satisfy $p_{\mathrm{FWE}}<0.05$

orbitofrontal cortex/subgenual anterior cingulate cortex, left temporal pole, left frontal operculum, and thalamus; Fig. 2, Table 3. High peak density was observed in the ventromedial prefrontal cortex (Fig. 1, lower left) and ventral striatum (Fig. 1, right), but spatial variability prevented the ventral striatum from achieving ALE convergence. This may be unsurprising, as a large number of exclusively ROI-based cue reactivity studies focused on these regions, particularly the ventral striatum, by extracting averaged activity from previously defined anatomical regions of interest. As above, these studies (e.g., [81, 82-84]) were not included as they do not lend themselves to the ALE meta-analytic technique. However, this body of cue reactivity work using a priori ventral striatal ROIs is generally consistent in showing attenuation to alcohol/drug cues using successful interventions (for reviews, see [31, 85]).

\section{Interventions on Delay Discounting: fMRI}

Manipulations targeting delay-of-gratification showed convergent results mostly along default mode midline structures, from medial and ventromedial prefrontal, anterior and posterior cingulate, and precuneus, with additional temporal and parietal findings; Fig. 3, Table 4.

\section{Co-occurrence of Intervention Effects}

Two convergence peaks from the two ALE analyses on cue reactivity and discounting were immediately adjacent in vmPFC but did not spatially overlap (although their extent may be limited by low available power). The pattern of results from these two types of interventions shows overlapping individual peaks (Fig. 4A) and spatial co-localization of ALE results in vmPFC (Fig. 4B).

\section{Risk of Bias}

Visual inspection of funnel plots suggested that both the cue reactivity and delay discounting study samples contained probable publication bias favoring positive effect sizes (Fig. 5). Orwin's fail-safe $\mathrm{N}$ analyses indicated that 53 and 69 studies would be required to reduce the mean effect sizes to 0.2 for cue reactivity and delay discounting, respectively. Note that one outlier in the delay discounting studies with $d=4.73$ [77] strongly influenced the mean, and reduced the required study number from 69 to 52 when removed. Two substantial sources of potential bias in neuroimaging studies affecting the weight of evidence are sample size and imaging threshold value. Consistent with the ongoing trend for 
Table 2 Delay discounting intervention studies

\begin{tabular}{|c|c|c|c|c|c|c|c|c|c|c|c|}
\hline $\begin{array}{l}\text { First } \\
\text { author }\end{array}$ & Year & $\mathrm{N}^{1}$ & Age $\pm \mathrm{SD}$ & $\begin{array}{l}\% \\
\text { male }\end{array}$ & $\begin{array}{l}\mathrm{DD} \\
\text { type }^{2}\end{array}$ & Delay $^{3}$ & Delayed amount & Intervention & $\begin{array}{l}\text { Intervention } \\
\text { cue type }\end{array}$ & $\begin{array}{l}\text { Contrast } \\
\text { conditions }\end{array}$ & WB threshold ${ }^{3}$ \\
\hline Boettiger & 2009 & $\begin{array}{l}9 \mathrm{AA}, \\
10 \mathrm{HC}\end{array}$ & $28.3 \pm 5.8$ & 58 & Fixed & $7-183$ & $\$ 2-\$ 100$ & $\begin{array}{l}50 \mathrm{mg} \\
\text { NTX }\end{array}$ & $\mathrm{n} / \mathrm{a}$ & $\begin{array}{l}\text { NTX versus } \\
\text { placebo, } \\
\text { now versus } \\
\text { later }\end{array}$ & $p_{\text {corr }}<0.001$ \\
\hline Peters & 2010 & $30 \mathrm{H}$ & 25.4 & 50 & IO & $1-233$ & $20.50 €-80.00 €$ & EFT & Text tag & $\begin{array}{c}\text { [Episodic }> \\
\text { control] }\end{array}$ & $\begin{array}{c}p_{\mathrm{FWE}}<0.05, \\
k=10\end{array}$ \\
\hline Benoit & 2011 & $12 \mathrm{H}$ & 27.3 & 33 & Fixed & $30-360$ & $£ 28-£ 65$ & EFT & Text tag & $\begin{array}{r}\text { [Imagine }> \\
\text { estimate] }\end{array}$ & $\begin{array}{c}p_{\text {uncorr }}<0.001 \\
k=10\end{array}$ \\
\hline Luo & 2014 & $15 \mathrm{H}$ & $33.6 \pm 7.7^{\mathrm{a}}$ & $59^{\mathrm{a}}$ & IO & $14-56$ & $\$ 20-\$ 65$ & EP & Face images & $\begin{array}{c}{[\text { Fearful }>} \\
\text { happy }]\end{array}$ & $\begin{array}{l}Z>2.3 \\
\quad p_{\mathrm{CC}}<0.05\end{array}$ \\
\hline Sasse & 2015 & $23 \mathrm{H}$ & $24.96 \pm 2.79$ & 52 & IO & $1-190$ & $20.50 €-79.50 €$ & EFT & Text tag & $\begin{array}{c}\text { [Episodic > } \\
\text { control] }\end{array}$ & $p_{\mathrm{FWE}}<0.05$ \\
\hline $\mathrm{Hu}$ & 2017 & $22 \mathrm{H}$ & $24 \pm 3$ & 36 & IO & $7-365$ & $>20 €$ & EFT & Text tag & $\begin{array}{c}\text { [Episodic }> \\
\text { control] }\end{array}$ & $\begin{array}{c}p_{\text {uncorr }}<0.001 \\
k=350\end{array}$ \\
\hline Sasse & 2017 & $22 \mathrm{HO}$ & $66.55 \pm 4.02$ & 41 & IO & $1-190$ & $20.50 €-79.50 €$ & EFT & Text tag & $\begin{array}{c}\text { [Episodic > } \\
\text { control] }\end{array}$ & $\begin{array}{c}p_{\text {uncorr }}<0.005 \\
\quad p_{\text {CCFWE }}<0.05\end{array}$ \\
\hline Wiehler & 2017 & $\begin{array}{c}23 \mathrm{PG}, 23 \\
\mathrm{HC}\end{array}$ & $29.08^{\mathrm{a}}$ & 100 & IO & $1-\sim 200$ & $>20 €$ & EFT & Text tag & $\begin{array}{c}\text { [Episodic }> \\
\text { control] }\end{array}$ & $p_{\text {FWE }}<0.05$ \\
\hline Wang & 2018 & $17 \mathrm{H}$ & $22.7 \pm 3.0$ & 41 & Fixed & $8-1110$ & $\$ 10-\$ 16,600$ & glucose & $\mathrm{n} / \mathrm{a}$ & $\begin{array}{l}\text { [Rinse > } \\
\quad \text { ingestion] }\end{array}$ & $\begin{array}{c}p_{\text {uncorr }}<0.001, \\
\quad p_{\text {CCFWE }}<0.05\end{array}$ \\
\hline
\end{tabular}

$\mathrm{AA}=$ abstinent alcoholics; $\mathrm{HC}=$ healthy control; $\mathrm{H}=$ healthy; $\mathrm{HO}=$ healthy older; $\mathrm{PG}=$ pathological gambler; $\mathrm{IO}=$ individually optimized, i.e., out-ofscanner DD parameterized trials for in-scanner DD; NTX = naltrexone; EFT = episodic future thinking; $\mathrm{EP}=$ emotional prime

${ }^{1}$ Including only subjects with useable fMRI data; ${ }^{2}$ used in-scanner; ${ }^{3}$ "later" option delay in days; ${ }^{4} \mathrm{WB}=$ whole brain (Subscripts indicate correction: corr $=$ corrected, $\mathrm{FWE}=$ family-wise error corrected, uncorr $=$ uncorrected, $\mathrm{CC}=$ cluster corrected)

${ }^{a}$ Provided only for initial group before exclusions

requiring greater subject numbers to meet stricter thresholds, our reviewed studies show a strong trend for larger samples with time (study $\mathrm{n}$ and publication year); $r(17)=.45, p=.053$. Half of the cue reactivity studies used uncorrected whole-brain thresholds, with the other half corrected either voxelwise or by using a cluster size requirement (garnering significant methodological discussion in recent years, (e.g., [86])); 78\% of the delay discounting studies used corrected thresholds. Cue reactivity and delay discounting studies did not differ in sample sizes, $p>.2$; mean $n$ s $28.4 \pm 8.0$ and $22.9 \pm$ 10.1 , respectively. Methodological differences particularly between randomized controlled trials (RCT; 6 studies) and others (13 studies) may have introduced bias. We might suspect smaller effect sizes in RCTs due to stricter randomization and more evenly distributed variability. Therefore, we tested for effect size differences between RCTs and non-RCTs across all studies reported here; $t(17)=1.39, p=.18$, or in the cue reactivity studies alone, $t(8)=1.52, p=.17$, but detected no differences. Regarding sample sizes for reported analyses, RCTs did not utilize more subjects than non-RCTs, $t(17)=0.48, p=.64$, mean $n \mathrm{~s}=27.3 \pm 5.3$ and $25.1 \pm$ 10.7 for RCT and non-RCT studies, respectively.

\section{Discussion}

The divergent methods used within these two categories of interventions or manipulations should identify convergent regions sensitive to treatments, yielding loci of responsive brain regions governing, 1) conditioned alcohol reward; 2) intertemporal choice (reward decision-making across the time domain, e.g., immediate vs. delayed rewards, or delay discounting); and 3) areas of overlap. Although these may appear to be divergent processes, both involve immediate reward signaling. However, intertemporal choice alone includes longer delays in pursuit of more abstract rewards. Thus, we may expect overlap of common processes, with divergence in brain regions relating chiefly to alcohol-specific reward, or to reward delay, respectively. Brain regions responding to both types of interventions thus represent putative reward decisionmaking targets germane to addiction treatment. With neural responses to treatment increasingly recognized as an objective metric for treatment efficacy [31], the loci identified here could facilitate the refinement of current treatments, and spatial targeting for future interventions. Publication bias was evident in both intervention types, but bias did not differ substantially between cue reactivity and delay discounting studies. 
Fig. 2 Alcohol cue reactivity interventions. Peaks from individual studies reporting responses to interventions for attenuating conditioned alcohol reward (4 mm radius spheres; yellow); convergent regions from ALE in red $\left(p_{\text {uncorr }}<0.001\right.$, extent $\left.=100 \mathrm{~mm}^{3}\right)$. White lines (center, sagittal plane) indicate slices displayed in axial (left) and coronal (right) views. MNI coordinates in white (left $\mathrm{z}$, middle $\mathrm{x}$, right $\mathrm{y}$ )

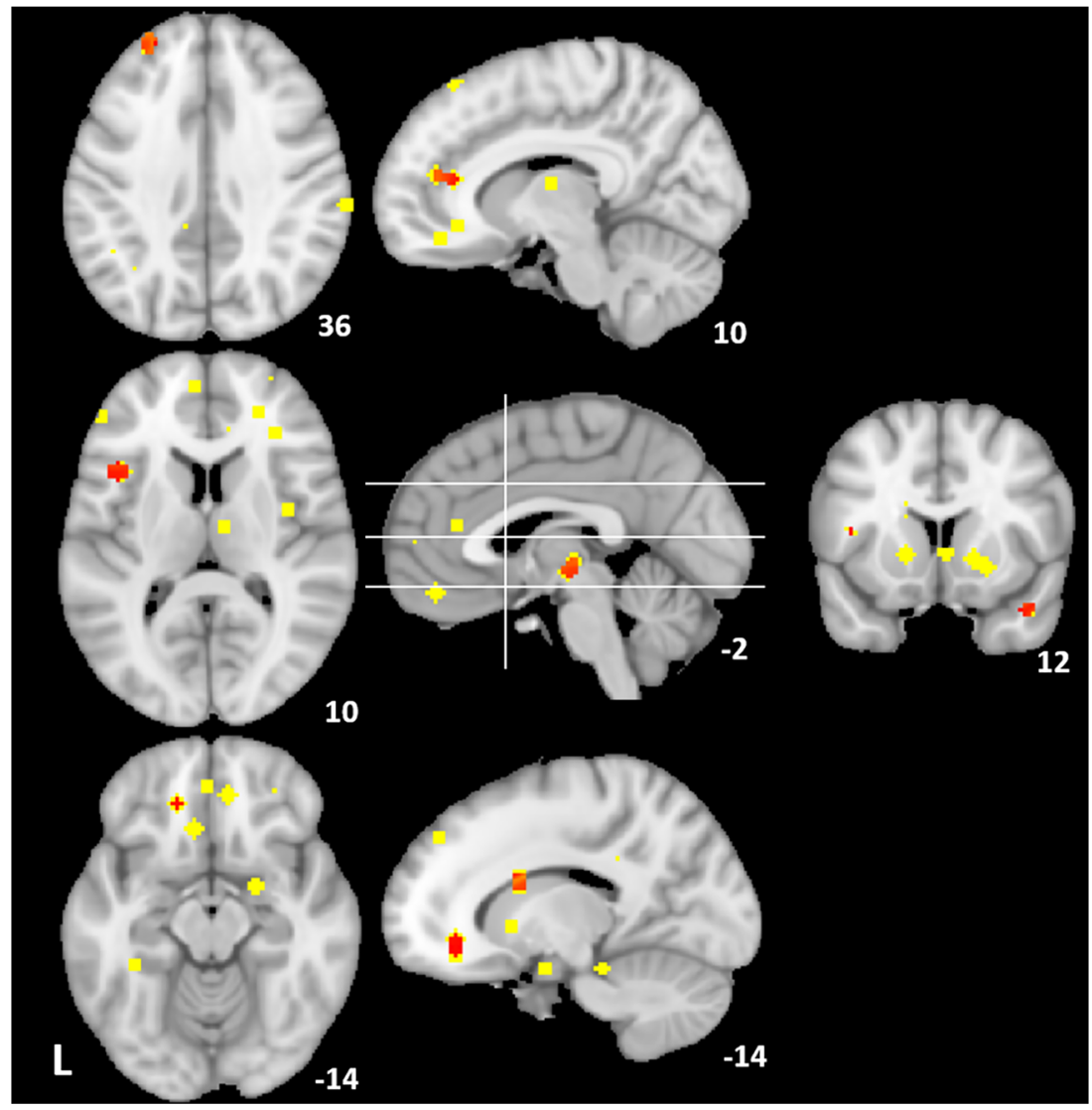

By examining effects of interventions targeting conditioned reward and decision-making in AUD, we aimed to identify brain areas responding to treatment-relevant interventions in two key domains of addiction-with the additional goal of identifying regions of overlap. Findings included evidence for intervention-related responses in 1) reward and salience networks, and dorsal striatum for cue reactivity interventions; 2) introspection and valuation-related areas for delay discounting interventions; and 3) co-occurrence within a key reward and valuation region: vmPFC. Although the ventral striatum did not reach statistical significance in the cue reactivity studies as we might expect from meta-analysis of cue-induced activation [85], we note that a number of peaks from individual studies occur within this area (Fig. 2, right), albeit with high spatial variability. Unexpectedly, neither frontoparietal network nor ventral striatal convergence was noted for the DD intervention studies, both of which are widely implicated in delay discounting processes [76, 87-89]. The general pattern of results here suggests that interventions on alcohol-conditioned cues are more specific to brain systems governing valuation and salience, whereas interventions on delay-of-gratification specifically are more concentrated in
Table 3 Cue reactivity intervention ALE results

\begin{tabular}{lllllll}
\hline Anatomical region & BA & $x$ & $y$ & $z$ & ALE & Volume $\left(\mathrm{mm}^{3}\right)$ \\
\hline L frontal operculum & - & -42 & 16 & 10 & 0.015 & 432 \\
L MFG & 9 & -28 & 48 & 36 & 0.013 & 376 \\
Ventromedial thalamus & - & -2 & -18 & -4 & 0.013 & 336 \\
L dorsal caudate & - & -16 & 8 & 20 & 0.013 & 304 \\
R lateral temporal gyrus & 22 & 40 & 14 & -26 & 0.012 & 280 \\
R dorsal ACC & 32 & 10 & 38 & 14 & 0.011 & 256 \\
L subgenual ACC/OFC & 10,11 & -14 & 38 & -8 & 0.010 & 248 \\
\hline
\end{tabular}

No clusters exceeded the cluster correction threshold $p_{\text {FWE }}<0.05$ (488 $\mathrm{mm}^{3}$ required). Coordinates in MNI space $\mathrm{BA}=$ Brodmann area $\mathrm{MFG}=$ middle frontal gyrus, $\mathrm{ACC}=$ anterior cingulate cortex, $\mathrm{OFC}=$ orbitofrontal cortex 
Fig. 3 Delay discounting interventions. Peaks from individual studies reporting responses to interventions for increasing delayed reward preference (4 $\mathrm{mm}$ radius spheres; yellow); convergent regions from ALE in red, $\left(p_{\text {uncorr }}<0.001\right.$, extent $\left.=100 \mathrm{~mm}^{3}\right)$. MNI coordinates shown in white $(\mathrm{z}$, except $\mathrm{x}$ lower right)

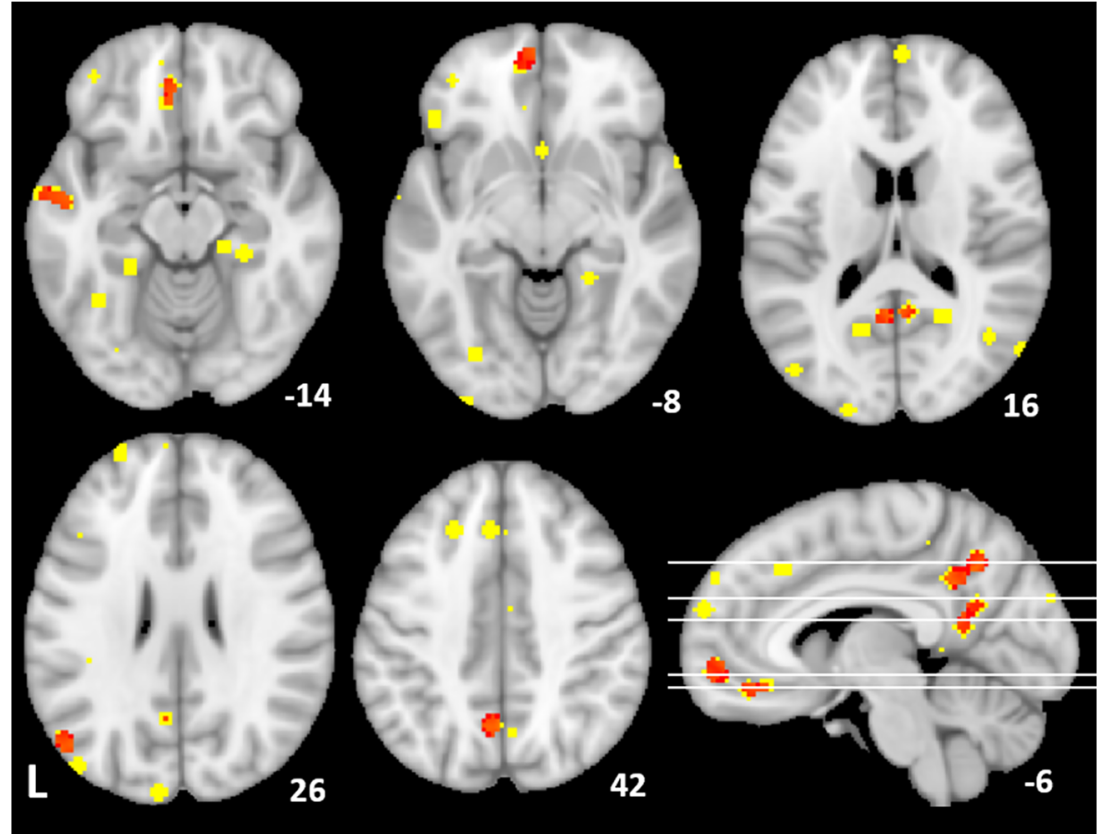

midline default mode regions. Importantly, co-occurrence between the two intervention types appears in the vmPFC, which is heavily implicated in subjective reward value [90] that underlies both incentive salience and reward decisionmaking processes [91-93]. Neither alcohol reward (and associated conditioning), nor impaired delay-of-gratification are likely sufficient for addiction, but both appear necessary. For example, a regular drinker who responsibly plans for the future does not necessarily suffer from AUD, nor does a nondrinking but irresponsible spender, necessarily, but the combination of high alcohol reward valuation and myopia for future consequences constitutes serious risk for addiction $[94,95]$. Here, brain regions responding to interventions on both traits show common effects in the vmPFC, suggesting a possible common process, while regions specific to each (striatum and dorsal ACC in cue reactivity, and PCC/precuneus for delay discounting) may indicate brain processes specific to those functions.

\section{Cue Reactivity}

Over time, and through the process of Pavlovian learning, a reward's associated sensory stimuli (e.g., sights, smells, tastes) become paired with (conditioned to) its reinforcing qualities (e.g., intoxication). These associations can be strong enough to invigorate reward seeking via "Pavlovian-to-instrumental transfer" (PIT; [96, 97]). The psychological and physiological responses to these alcohol-associated cues are thus implicated in both subjective craving and treatment relapse [21, 27, 98-101], but also see [102, 103]. Several decades of research in both animals and humans now show that reward- (drug-) cue exposure is itself sufficient to induce activity in the mesolimbic dopamine system [104], which is understood to partly comprise projections from the midbrain's ventral tegmental area to the ventral striatum (ventral putamen and caudate, to include the nucleus accumbens; see [105] for an overview). Inactivation or dopamine blockade of these regions
Table 4 Delay discounting intervention ALE results

\begin{tabular}{lllllll}
\hline Anatomical region & BA & $x$ & $y$ & $z$ & ALE & Volume $\left(\mathrm{mm}^{3}\right)$ \\
\hline L PCC/precuneus & 23,31 & -6 & -60 & 44 & 0.015 & $928^{*}$ \\
L middle frontopolar gyrus & 10 & -6 & 58 & -6 & 0.015 & $664^{*}$ \\
L \& R PCC/precuneus & 23,31 & -4 & -54 & 18 & 0.012 & $656^{*}$ \\
L STG & 22 & -54 & -8 & -14 & 0.011 & $592^{*}$ \\
L MTG/angular gyrus & 37,39 & -52 & -70 & 26 & 0.013 & 528 \\
L vmPFC, subgenual ACC & 10,11 & -6 & 42 & -14 & 0.010 & 272 \\
\hline
\end{tabular}

$\mathrm{BA}=$ Brodmann area $\mathrm{PCC}=$ posterior cingulate cortex, $\mathrm{vmPFC}=$ ventromedial prefrontal cortex, $\mathrm{STG}=$ superior temporal gyrus, $\mathrm{MTG}=$ middle temporal gyrus, $\mathrm{ACC}=$ anterior cingulate cortex

*Exceeds the cluster correction threshold $p_{\mathrm{FWE}}<0.05$. Coordinates in MNI space 
Fig. 4 Intervention effects in $v m P F C$. (A) Individual peaks from incentive salience and delayof-gratification intervention studies co-localized in ventral prefrontal cortex from subgenual ACC to frontopolar cortex (blue ellipse); (B) ALE results ( $p_{\text {uncorr }}$ $<0.001$, extent $=100 \mathrm{~mm}^{3}$ ) indicate $\mathrm{VmPFC}$ sensitivity to interventions. Interventions on alcohol cue reactivity and delay discounting are shown in red and green, respectively, for individual peaks (A) and ALE clusters (B)

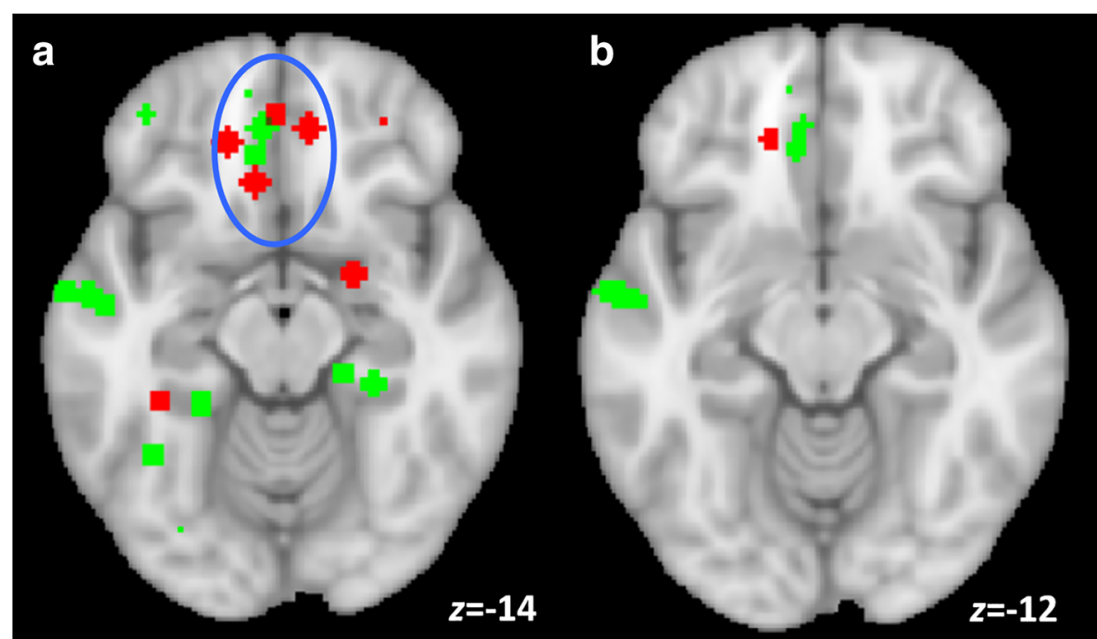

also eliminates cue-invigorated reward seeking (i.e., PIT; $[106,107,108])$.

Two predominant theoretical camps evolved to explain the behavioral and psychological significance of mesolimbic dopamine transmission from drug conditioned stimuli. The "incentive salience" camp [17, 18] focuses on the motivational ("drug wanting") significance, while "prediction error" theorists $[109,110]$ focus on mechanisms of reward learning that is not necessarily linked to wanting. Both nevertheless recognize that activity in these regions reflect a learned relationship between drug (reward) and the drug's associated sensory stimuli-and that this learning impacts drug-relevant behavior. With this background, it is hardly a surprise that many of the studies we found concentrate on the ventral striatum $a$ priori.

At the same time, the mesolimbic dopamine circuit is only part of this system [111]. In particular, descending (glutamatergic) fibers project from frontal cortex to the striatum, with those from ventromedial and orbitofrontal cortex targeting the ventral and medial striatum. Activity in the ventromedial prefrontal area of convergence detected here (sometimes called medial orbitofrontal cortex) has been linked to perceived reward value [111-117], with ventral prefrontal cortex proposed to be an important site for "common neural currency" $[118,119]$ that works in concert with the ventral striatum to update reward value. Thus, the vmPFC's relevance to conditioned reward and valuation is well-established, and its importance to alcoholism treatment and relapse is also now evident (Seo, et al., 2013).

\section{Delay Discounting}

Other recent meta-analytic findings suggest that mPFC and PCC both activate during discounting, and our results indicate that these regions respond to therapeutic interventions for increasing delay-of-gratification. Prior work [57] shows that activation within the impulsive " $\beta$ system" (regions activating to immediate reward availability; [87]) closely maps to the same $\mathrm{mPFC}$ regions, albeit contralateral to the ventromedial prefrontal cortex (vmPFC) result. Similarly, "subjective reward" (the objective reward amount weighted by discount functions; [120]) maps onto both mPFC and posterior cingulate cortex (PCC) in regions close to our findings for regions sensitive to intervention. Contrary to conventional expectations, the locations of brain responses to delay-of-gratification interventions showed no convergence with the classical wanting/reward region (ventral striatum), or with dorsolateral prefrontal cortex/ frontoparietal network (linked to executive control),
Fig. 5 Funnel plots of Cohen's d by sample size. Both types of intervention studies showed asymmetry, with underrepresentation of small studies with small effect sizes. Mean effect sizes indicated as dashed lines
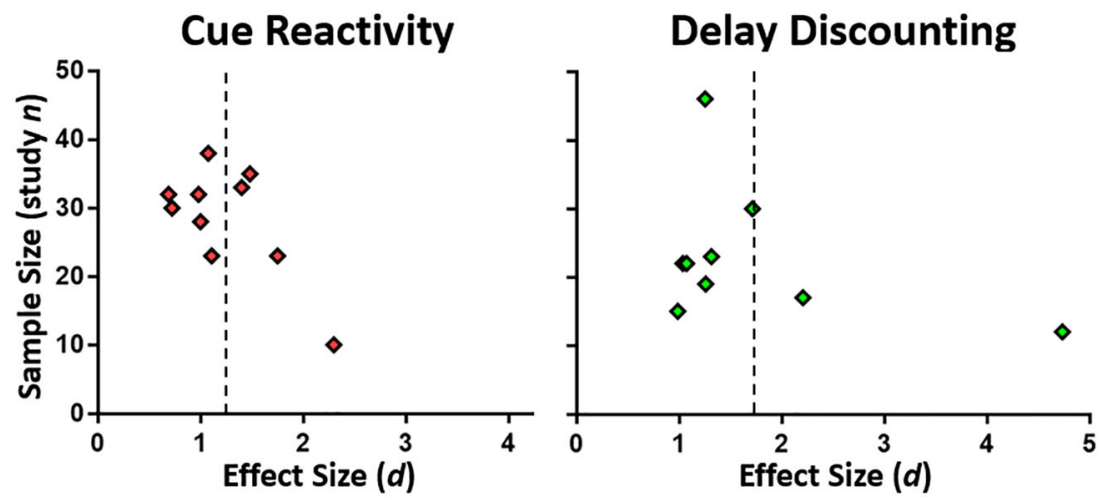
suggesting that reward drive and executive control regions may be less involved than the midline default mode network for increasing delayed reward preference. Here, the finding unique to increased delay-of-gratification is the $\mathrm{PCC} /$ precuneus: the hub of the posterior default mode network [121]. Although the default mode network is widely thought to be more active at rest and to oppose the task-positive frontoparietal network, more recent work shows default mode coupling with the frontoparietal network for internally focused cognition [122]. The PCC also appears central to environmental monitoring/change detection, including when it involves reward choice [123, 124], suggesting its key role in decision-making. The PCC/precuneus is specifically involved in episodic memory retrieval [125], with the anterior default mode, i.e., vmPFC, relatively less implicated. Thus, the $\mathrm{PCC} /$ precuneus is deeply rooted in a host of functions critical to intertemporal choice - a complex decision process requiring the integration of memory, probability estimation, ambiguity assessment, perspective-taking of the future self, constructing hypothetical future environments, estimating future competing reinforcers, all within the context of dynamically changing contingencies to establish "goal value." Interventions capable of increasing the subjective value of future rewards would be expected to enhance posterior default mode function, particularly in light of its putative role in change detection and policy selection [123].

Broadly, brain regions implicated in intertemporal choice in healthy subjects fall into default mode, frontoparietal and salience networks (as defined by [126]), with the majority of the peaks for subjective value, objective value, choice difficulty, and the (impatient) " $\beta$ system" appearing in default mode regions, based on recent meta-analyses [57]. Peaks identified by Schüller and colleagues in the in $\beta$ system and subjective value studies showed similar convergence to the current findings in midline default mode regions, in both anterior (vmPFC, mPFC, subgenual ACC) and posterior (PCC/ precuneus) hubs. Thus, although we did not find frontoparietal or striatal reward/wanting peaks, as identified by Schüller and colleagues, it is plausible that brain effects of intervention are discrete from those used to actually perform discounting tasks. Here, we find intervention effects coalescing along midline anterior and posterior default mode regions, suggesting that these areas both actively participate in discounting, and are amenable to manipulation.

Accumulating evidence identifies impaired delay-ofgratification to be a common mechanism underlying AUD and other addictions as a trans-disease process [42, 45, 46, 127], and one that longitudinally predicts drug use/abuse [128-130], as well as treatment outcomes [49-51, 131, 132]. Episodic future thinking comprised the majority of the reviewed interventions on delay-of-gratification, and the majority of the EFT studies we reported included explicit instructions for subjects to elaborate and visualize the imagined future. While EFT scenarios often imply the participation of the self, explicitly including the self into intertemporal choice paradigms offers considerable therapeutic promise [133-135]. Highlighting the role of midline default mode regions in considering one's future, subjects' rostral ACC activation during present- and future-self-description predicted later delay discounting [134], and more similarity in activation to future and present self-description corresponded to less discounting. This suggested the possibility that discounting behavior indexed future self-continuity [135], such that mental constructions of one's future containing more vivid and integrated future selves indicate greater future self-identification. Given the well-established role of the default network in introspective [121], prospective [136], and self-referential processing $[137,138]$, it is unsurprising that interventions for increasing delay-of-gratification act in midline default mode regions. The PCC may be particularly involved with introspective delay-ofgratification brain processes (but not necessarily alcoholconditioned reward processes), and therefore could represent a site of action for techniques designed to enhance the salience of future rewards, e.g., future-oriented motivational interviewing-based methods [139, 140].

\section{Co-localization}

The convergent peaks of intervention effects on cue reactivity and delay discounting co-localize in the right vmPFC, at the locations of decision value and goal value (the net value of a reward decision-making action, and willingness to pay, respectively), as identified in a food purchase task [111]. Interestingly, the individual peaks from the two types of intervention studies lie along the border $(z=-16$; Fig. 4$)$ between the orbitofrontal and anterior medial default mode networks, as defined in resting state functional connectivity [126]. The functionally defined orbitofrontal network contains limbic cortex that responds to imagined reinforcer value at the time of choice [113, 114, 141], perceived pleasantness [142], alcohol wanting [23], and more broadly appears to be at the nexus of a range of hedonic experiences governed by primary and secondary reinforcers (for review, see [143]). Our current findings are located at the physical interface of these two key networks governing introspective decision-making, conditioned reward, and valuation.

We restricted our investigation to domains most implicated in positive reinforcement-related AUD, i.e., a "reward drinking" phenotype $[12,13]$. Although the emotionality domain may appear to be largely independent [8, 9], important interactions with executive function and cue reactivity have been found. For example, limbic responses to emotional cues are differentially sensitive to modulation by alcohol cues in AUD versus controls [144], and the classically reward-associated midbrain is sensitive to emotional cues during an executive control task in AUD [145]. Germane to recovery outcomes, 
abstinent AUD showed less hippocampal connectivity than controls, with longer periods of sobriety corresponding with reduced fusiform activation to emotional face stimuli [146]. While there is little extant neuroimaging of negative emotionality and manipulations of delay-of-gratification, one of the reviewed studies indicated that an emotional fear prime was associated with dorsal ACC and PCC activation and increased delay-of-reward, which may be governed by the interaction between emotion and executive function [80].

\section{Limitations}

The study designs used in the reviewed cue reactivity studies reflect pre- versus postinterventions that may more closely resemble practicable therapeutic interventions than the delay discounting studies; we were limited by the published literature to acute interventions in these cases. Although the study designs were not truly analogous, we believe the more consistent convergence in the delay discounting interventions argues for confidence in those effects. Future studies of pre- and postintervention effects on delay-of-gratification for addiction to alcohol and other drugs will help to corroborate this observation. Our comparison of results from two populations (AUD/heavy drinkers in cue reactivity and mostly healthy controls in delay discounting) could limit our interpretations insofar as activation in regions governing delay discounting differ between healthy controls and AUD/heavy drinkers. Prior work in abstinent AUD and controls indicate more AUD activation during immediate choices in lateral orbitofrontal cortex relative to controls [147], and other work suggests that delay-of-gratification activation differs as a function of AUD severity in the supplementary motor area, insula/ posterior orbitofrontal cortex, inferior frontal gyrus, cuneus [148], and superior frontal gyrus, paracingulate gyrus, and frontal pole [149]. These clusters lie outside the regions identified here, mitigating the concern of differential response by group. The only study reported here potentially informing this question is the Boettiger study [60], which found no group $\times$ naltrexone interaction in the ROI analysis. Ultimately, we believe that the approach remains informative insofar as we have no reason to believe that there are substantially different anatomic systems across populations (i.e., the functional anatomy should, by and large, be similar between populations, even if level of function is not). The ALE analyses were somewhat underpowered [63], limited by available studies. Although we acknowledge that robust ALE findings will require additional studies, we believe that this early-stage attempt to locate intervention effects is nonetheless worthwhile - and note that four of the discounting intervention clusters exceeded the recommended threshold. Some studies included in the analyses, particularly the older ones, utilized fMRI statistical thresholds lower than commonly accepted today [150]. While the older studies potentially inject more type I error into our analyses, this effect should theoretically be randomly located, and therefore have little overall effect on analyses of convergence (for excellent commentary on these issues, see [151]).

\section{Conclusion}

We identified regions responding to interventions, indicating therapeutic potential, that were common to both incentive salience and (a form of) executive function in the vmPFC. Additionally, we found convergent peaks from interventions specific to delay discounting in PCC/precuneus, indicating particular sensitivity to delay-of-gratification manipulations at this critical network hub. These early findings indicate that manipulations targeting reward decision-making should elicit effects in vmPFC, whereas manipulations designed to change future orientation or prospection should increase activity in vmPFC and PCC/precuneus. Thus, we hope that our findings provide a useful guide to facilitate validation and/or spatial brain targeting for future interventions, and ultimately therapeutic manipulations on AUD and addictions.

Acknowlegments We gratefully acknowledge Katherine Benson, George Chittum, and Dr. Melissa Cyders for their assistance with manuscript preparation. Supported by R00 AA023296 to BGO and P60 AA007611 to DAK.

\section{References}

1. Witkiewitz K, Litten RZ, Leggio L. Advances in the science and treatment of alcohol use disorder. Sci Adv. 2019;5(9):eaax4043.

2. Carvalho AF, Heilig M, Perez A, Probst C, Rehm J. Alcohol use disorders. Lancet. 2019;394(10200):781-92.

3. Czapla M, Simon JJ, Richter B, Kluge M, Friederich HC, Herpertz $\mathrm{S}$, et al. The impact of cognitive impairment and impulsivity on relapse of alcohol-dependent patients: implications for psychotherapeutic treatment. Addict Biol. 2016;21(4):873-84.

4. Hunt WA, Barnett LW, Branch LG. Relapse rates in addiction programs. J Clin Psychol. 1971;27(4):455-6.

5. Anton RF, O'Malley SS, Ciraulo DA, Cisler RA, Couper D, Donovan DM, et al. Combined pharmacotherapies and behavioral interventions for alcohol dependence: the COMBINE study: a randomized controlled trial. JAMA. 2006;295(17):2003-17.

6. Costello RM, Biever P, Baillargeon JG. Alcoholism treatment programming: Historical trends and modern approaches. Alcoholism: Clinical and Experimental Research. 1977;1(4): 311-8.

7. APA (APA). Diagnostic and statistical manual of mental disorders (5th ed.). Arlington: American Psychiatric Publishing; 2013.

8. Kwako LE, Momenan R, Litten RZ, Koob GF, Goldman D. Addictions Neuroclinical Assessment: A Neuroscience-Based Framework for Addictive Disorders. Biol Psychiatry. 2016;80(3):179-89.

9. Kwako LE, Schwandt ML, Ramchandani VA, Diazgranados N, Koob GF, Volkow ND, et al. Neurofunctional Domains Derived From Deep Behavioral Phenotyping in Alcohol Use Disorder. Am J Psychiatry. 2019; 176(9):744-753. appiajp201818030357. 
10. Cloninger CR. Neurogenetic adaptive mechanisms in alcoholism. Science. 1987;236(4800):410-6.

11. Babor TF, Hofmann M, DelBoca FK, Hesselbrock V, Meyer RE, Dolinsky ZS, et al. Types of alcoholics, I: Evidence for an empirically derived typology based on indicators of vulnerability and severity. Archives of general psychiatry. 1992;49(8):599-608.

12. Mann K, Kiefer F, Smolka M, Gann H, Wellek S, Heinz A. Searching for responders to acamprosate and naltrexone in alcoholism treatment: rationale and design of the PREDICT study. Alcohol Clin Exp Res. 2009;33(4):674-83.

13. Mann K, Roos CR, Hoffmann S, Nakovics H, Lemenager T, Heinz A, et al. Precision Medicine in Alcohol Dependence: A Controlled Trial Testing Pharmacotherapy Response Among Reward and Relief Drinking Phenotypes. Neuropsychopharmacology. 2018;43(4):891-9.

14. Ooteman W, Koeter M, Verheul R, Schippers G, Van den Brink W. Development and validation of the Amsterdam Motives for Drinking Scale (AMDS): an attempt to distinguish relief and reward drinkers. Alcohol Alcohol. 2006;41(3):284-92.

15. Foulds J, Newton-Howes G, Guy NH, Boden JM, Mulder RT. Dimensional personality traits and alcohol treatment outcome: a systematic review and meta-analysis. Addiction. 2017;112(8): 1345-57.

16. Burnette EM, Grodin EN, Lim AC, MacKillop J, Karno MP, Ray LA. Association between impulsivity and neural activation to alcohol cues in heavy drinkers. Psychiatry Res Neuroimaging. 2019;293:110986.

17. Robinson TE, Berridge KC. The neural basis of drug craving: an incentive-sensitization theory of addiction. Brain Res Brain Res Rev. 1993;18(3):247-91.

18. Robinson TE, Berridge KC. The incentive sensitization theory of addiction: some current issues. Philos Trans R Soc Lond B Biol Sci. 2008;363(1507):3137-46.

19. Engels RCME, Hermans R, Van Baaren RB, Hollenstein T, Bot SM. Alcohol portrayal on television affects actual drinking behaviour. Alcohol and Alcoholism. 2009;44(3):244-9.

20. Koordeman R, Anschutz DJ, van Baaren RB, Engels RCME. Effects of alcohol portrayals in movies on actual alcohol consumption: an observational experimental study. Addiction. 2011;106(3):547-54.

21. Rohsenow DJ, Monti PM, Rubonis AV, Sirota AD, Niaura RS, Colby SM, et al. Cue reactivity as a predictor of drinking among male alcoholics. Journal of Consulting and Clinical Psychology. 1994;62(3):620.

22. Kaplan RF, Meyer RE, Stroebel CF. Alcohol dependence and responsivity to an ethanol stimulus as predictors of alcohol consumption. British Journal of Addiction. 1983;78(3):259-67.

23. Oberlin BG, Dzemidzic M, Harezlak J, Kudela MA, Tran SM, Soeurt CM, et al. Corticostriatal and Dopaminergic Response to Beer Flavor with Both fMRI and [(11) C]raclopride Positron Emission Tomography. Alcohol Clin Exp Res. 2016;40(9): 1865-73.

24. Oberlin BG, Dzemidzic M, Tran SM, Soeurt CM, Albrecht DS, Yoder KK, et al. Beer flavor provokes striatal dopamine release in male drinkers: mediation by family history of alcoholism. Neuropsychopharmacology. 2013;38(9):1617-24.

25. Oberlin BG, Dzemidzic M, Tran SM, Soeurt CM, O'Connor SJ, Yoder KK, et al. Beer self-administration provokes lateralized nucleus accumbens dopamine release in male heavy drinkers. Psychopharmacology (Berl). 2015;232(5):861-70.

26. Courtney AL, Rapuano KM, Sargent JD, Heatherton TF, Kelley WM. Reward system activation in response to alcohol advertisements predicts college drinking. Journal of Studies on Alcohol and Drugs. 2018;79(1):29-38.

27. Grüsser SM, Wrase J, Klein S, Hermann D, Smolka MN, Ruf M, et al. Cue-induced activation of the striatum and medial prefrontal cortex is associated with subsequent relapse in abstinent alcoholics. Psychopharmacology (Berl). 2004;175(3):296-302.

28. Dager AD, Anderson BM, Rosen R, Khadka S, Sawyer B, Jiantonio-Kelly RE, et al. Functional magnetic resonance imaging (fMRI) response to alcohol pictures predicts subsequent transition to heavy drinking in college students. Addiction. 2014;109(4): 585-95.

29. Claus ED, Ewing SW, Filbey FM, Sabbineni A, Hutchison KE. Identifying neurobiological phenotypes associated with alcohol use disorder severity. Neuropsychopharmacology. 2011;36(10): 2086-96.

30. Brumback T, Squeglia LM, Jacobus J, Pulido C, Tapert SF, Brown SA. Adolescent heavy drinkers' amplified brain responses to alcohol cues decrease over one month of abstinence. Addictive Behaviors. 2015;46:45-52.

31. Cabrera EA, Wiers CE, Lindgren E, Miller G, Volkow ND, Wang GJ. Neuroimaging the Effectiveness of Substance Use Disorder Treatments. J Neuroimmune Pharmacol. 2016;11(3):408-33.

32. Harden PW, Pihl RO. Cognitive function, cardiovascular reactivity, and behavior in boys at high risk for alcoholism. J Abnorm Psychol. 1995;104(1):94-103.

33. Iacono WG, Malone SM, McGue M. Behavioral disinhibition and the development of early-onset addiction: common and specific influences. Annu Rev Clin Psychol. 2008;4:325-48.

34. Gierski F, Hubsch B, Stefaniak N, Benzerouk F, Cuervo-Lombard $\mathrm{C}$, Bera-Potelle C, et al. Executive functions in adult offspring of alcohol-dependent probands: toward a cognitive endophenotype? Alcohol Clin Exp Res. 2013;37 Suppl 1:E356-63.

35. Young SE, Friedman NP, Miyake A, Willcutt EG, Corley RP, Haberstick BC, et al. Behavioral disinhibition: liability for externalizing spectrum disorders and its genetic and environmental relation to response inhibition across adolescence. J Abnorm Psychol. 2009;118(1):117-30.

36. Le Berre AP, Fama R, Sullivan EV. Executive Functions, Memory, and Social Cognitive Deficits and Recovery in Chronic Alcoholism: A Critical Review to Inform Future Research. Alcohol Clin Exp Res. 2017;41(8):1432-43.

37. SAMHSA. 2015 National Survey on Drug Use and Health (NSDUH). 2015.

38. Petry NM. Delay discounting of money and alcohol in actively using alcoholics, currently abstinent alcoholics, and controls. Psychopharmacology (Berl). 2001;154(3):243-50.

39. Bjork JM, Hommer DW, Grant SJ, Danube C. Impulsivity in abstinent alcohol-dependent patients: relation to control subjects and type 1-/type 2-like traits. Alcohol. 2004;34(2-3):133-50.

40. Kirby KN, Petry NM. Heroin and cocaine abusers have higher discount rates for delayed rewards than alcoholics or non-drugusing controls. Addiction. 2004;99(4):461-71.

41. Mitchell JM, Fields HL, D'Esposito M, Boettiger CA. Impulsive responding in alcoholics. Alcohol Clin Exp Res. 2005;29(12): 2158-69.

42. MacKillop J, Amlung MT, Few LR, Ray LA, Sweet LH, Munafo MR. Delayed reward discounting and addictive behavior: a metaanalysis. Psychopharmacology (Berl). 2011;216(3):305-21.

43. Moody L, Franck C, Hatz L, Bickel WK. Impulsivity and polysubstance use: A systematic comparison of delay discounting in mono-, dual-, and trisubstance use. Experimental and clinical psychopharmacology. 2016;24(1):30.

44. Vuchinich RE, Simpson CA. Hyperbolic temporal discounting in social drinkers and problem drinkers. Experimental Clinical Psychopharmacology. 1998;6(3):292.

45. Amlung M, Vedelago L, Acker J, Balodis I, MacKillop J. Steep delay discounting and addictive behavior: a meta-analysis of continuous associations. Addiction. 2017;112(1):51-62.

46. Bickel WK, Koffarnus MN, Moody L, Wilson AG. The behavioral- and neuro-economic process of temporal discounting: 
A candidate behavioral marker of addiction. Neuropharmacology. 2014;76 Pt B:518-27.

47. Bickel WK, Snider SE, Quisenberry AJ, Stein JS. Reinforcer pathology: the behavioral economics of abuse liability testing. Clinical Pharmacology Therapeutics. 2017;101(2):185-7.

48. Sheffer CE, Christensen DR, Landes R, Carter LP, Jackson L, Bickel WK. Delay discounting rates: a strong prognostic indicator of smoking relapse. Addict Behav. 2014;39(11):1682-9.

49. Yoon JH, Higgins ST, Heil SH, Sugarbaker RJ, Thomas CS, Badger GJ. Delay discounting predicts postpartum relapse to cigarette smoking among pregnant women. Exp Clin Psychopharmacol. 2007;15(2):176-86.

50. MacKillop J, Kahler CW. Delayed reward discounting predicts treatment response for heavy drinkers receiving smoking cessation treatment. Drug Alcohol Depend. 2009;104(3):197-203.

51. Washio Y, Higgins ST, Heil SH, McKerchar TL, Badger GJ, Skelly JM, et al. Delay discounting is associated with treatment response among cocaine-dependent outpatients. Exp Clin Psychopharmacol. 2011;19(3):243-8.

52. Sheffer C, Mackillop J, McGeary J, Landes R, Carter L, Yi R, et al. Delay discounting, locus of control, and cognitive impulsiveness independently predict tobacco dependence treatment outcomes in a highly dependent, lower socioeconomic group of smokers. Am J Addict. 2012;21(3):221-32.

53. Stein JS, Wilson AG, Koffarnus MN, Daniel TO, Epstein LH, Bickel WK. Unstuck in time: episodic future thinking reduces delay discounting and cigarette smoking. Psychopharmacology (Berl). 2016;233(21-22):3771-8.

54. Wesley MJ, Bickel WK. Remember the future II: meta-analyses and functional overlap of working memory and delay discounting. Biol Psychiatry. 2014;75(6):435-48.

55. Carter RM, Meyer JR, Huettel SA. Functional neuroimaging of intertemporal choice models: a review. Journal of Neuroscience, Psychology, and Economics. 2010;3(1):27-45.

56. Frost R, McNaughton N. The neural basis of delay discounting: A review and preliminary model. Neurosci Biobehav Rev. 2017;79: 48-65.

57. Schüller CB, Kuhn J, Jessen F, Hu X. Neuronal correlates of delay discounting in healthy subjects and its implication for addiction: an ALE meta-analysis study. Am J Drug Alcohol Abuse. 2019;45(1):51-66.

58. Coles AS, Kozak K, George TP. A review of brain stimulation methods to treat substance use disorders. Am J Addict. 2018;27(2):71-91.

59. Liberati A, Altman DG, Tetzlaff J, Mulrow C, Gotzsche PC, Ioannidis JP, et al. The PRISMA statement for reporting systematic reviews and meta-analyses of studies that evaluate health care interventions: explanation and elaboration. PLoS Med. 2009;6(7): e1000100.

60. Boettiger CA, Kelley EA, Mitchell JM, D'Esposito M, Fields HL. Now or Later? An fMRI study of the effects of endogenous opioid blockade on a decision-making network. Pharmacol Biochem Behav. 2009;93(3):291-9.

61. Radua J, Mataix-Cols D, Phillips ML, El-Hage W, Kronhaus DM, Cardoner N, et al. A new meta-analytic method for neuroimaging studies that combines reported peak coordinates and statistical parametric maps. Eur Psychiatry. 2012;27(8):605-11.

62. Eickhoff SB, Laird AR, Grefkes C, Wang LE, Zilles K, Fox PT. Coordinate-based activation likelihood estimation meta-analysis of neuroimaging data: a random-effects approach based on empirical estimates of spatial uncertainty. Hum Brain Mapp. 2009;30(9):2907-26.

63. Eickhoff SB, Nichols TE, Laird AR, Hoffstaedter F, Amunts K, Fox PT, et al. Behavior, sensitivity, and power of activation likelihood estimation characterized by massive empirical simulation. Neuroimage. 2016;137:70-85.
64. Jennings RG, Van Horn JD. Publication bias in neuroimaging research: implications for meta-analyses. Neuroinformatics. 2012;10(1):67-80.

65. Orwin RG. A fail-safe $\mathrm{N}$ for effect size in meta-analysis. Journal of educational statistics. 1983;8(2):157-9.

66. Cohen J. Statistical power analysis for the behavioral sciences. New York: Academic Press; 1969.

67. Langosch JM, Spiegelhalder K, Jahnke K, Feige B, Regen W, Kiemen A, et al. The impact of acamprosate on cue reactivity in alcohol dependent individuals: a functional magnetic resonance imaging study. J Clin Psychopharmacol. 2012;32(5):661-5.

68. Wiers CE, Ludwig VU, Gladwin TE, Park SQ, Heinz A, Wiers $\mathrm{RW}$, et al. Effects of cognitive bias modification training on neural signatures of alcohol approach tendencies in male alcoholdependent patients. Addict Biol. 2015;20(5):990-9.

69. Kirsch M, Gruber I, Ruf M, Kiefer F, Kirsch P. Real-time functional magnetic resonance imaging neurofeedback can reduce striatal cue-reactivity to alcohol stimuli. Addict Biol. 2016;21(4): 982-92.

70. Herremans SC, Van Schuerbeek P, De Raedt R, Matthys F, Buyl R, De Mey J, et al. The Impact of Accelerated Right Prefrontal High-Frequency Repetitive Transcranial Magnetic Stimulation (rTMS) on Cue-Reactivity: An fMRI Study on Craving in Recently Detoxified Alcohol-Dependent Patients. PLoS One. 2015;10(8):e0136182.

71. Kearney-Ramos TE, Dowdle LT, Lench DH, Mithoefer OJ, Devries WH, George MS, et al. Transdiagnostic Effects of Ventromedial Prefrontal Cortex Transcranial Magnetic Stimulation on Cue Reactivity. Biol Psychiatry Cogn Neurosci Neuroimaging. 2018;3(7):599-609.

72. Braus DF, Wrase J, Grusser S, Hermann D, Ruf M, Flor H, et al. Alcohol-associated stimuli activate the ventral striatum in abstinent alcoholics. J Neural Transm. 2001;108(7):887-94.

73. Wiehler A, Petzschner FH, Stephan KE, Peters J. Episodic Tags Enhance Striatal Valuation Signals during Temporal Discounting in pathological Gamblers. eNeuro. 2017;4(3): ENEURO.0159-17

74. Hu X, Uhle F, Fliessbach K, Wagner M, Han Y, Weber B, et al. Reduced future-oriented decision making in individuals with subjective cognitive decline: A functional MRI study. Alzheimers Dement (Amst). 2017;6:222-31.

75. Lang PJ, Bradley MM, Cuthbert BN, Attention. International affective picture system (IAPS): Technical manual and affective ratings. NIMH Center for the Study of Emotion. 1997;1:39-58.

76. Peters J, Büchel C. Episodic future thinking reduces reward delay discounting through an enhancement of prefrontal-mediotemporal interactions. Neuron. 2010;66(1):138-48.

77. Benoit RG, Gilbert SJ, Burgess PW. A neural mechanism mediating the impact of episodic prospection on farsighted decisions. $\mathrm{J}$ Neurosci. 2011;31(18):6771-9.

78. Sasse LK, Peters J, Buchel C, Brassen S. Effects of prospective thinking on intertemporal choice: The role of familiarity. Hum Brain Mapp. 2015;36(10):4210-21.

79. Sasse LK, Peters J, Brassen S. Cognitive Control Modulates Effects of Episodic Simulation on Delay Discounting in Aging. Front Aging Neurosci. 2017;9:58.

80. Luo S, Ainslie G, Monterosso J. The behavioral and neural effect of emotional primes on intertemporal decisions. Soc Cogn Affect Neurosci. 2014;9(3):283-91.

81. Myrick H, Anton RF, Li X, Henderson S, Randall PK, Voronin K. Effect of naltrexone and ondansetron on alcohol cue-induced activation of the ventral striatum in alcohol-dependent people. Arch Gen Psychiatry. 2008;65(4):466-75.

82. Mann K, Vollstadt-Klein S, Reinhard I, Lemenager T, FauthBuhler M, Hermann D, et al. Predicting naltrexone response in alcohol-dependent patients: the contribution of functional 
magnetic resonance imaging. Alcohol Clin Exp Res. 2014;38(11): 2754-62.

83. Myrick H, Li X, Randall PK, Henderson S, Voronin K, Anton RF. The effect of aripiprazole on cue-induced brain activation and drinking parameters in alcoholics. J Clin Psychopharmacol. 2010;30(4):365-72.

84. Schacht JP, Randall PK, Latham PK, Voronin KE, Book SW, Myrick H, et al. Predictors of Naltrexone Response in a Randomized Trial: Reward-Related Brain Activation, OPRM1 Genotype, and Smoking Status. Neuropsychopharmacology. 2017;42(13):2654.

85. Schacht JP, Anton RF, Myrick H. Functional neuroimaging studies of alcohol cue reactivity: a quantitative meta-analysis and systematic review. Addict Biol. 2013;18(1):121-33.

86. Woo CW, Krishnan A, Wager TD. Cluster-extent based thresholding in fMRI analyses: pitfalls and recommendations. Neuroimage. 2014;91:412-9.

87. McClure SM, Laibson DI, Loewenstein G, Cohen JD. Separate neural systems value immediate and delayed monetary rewards. Science. 2004;306(5695):503-7.

88. McClure SM, Ericson KM, Laibson DI, Loewenstein G, Cohen JD. Time discounting for primary rewards. J Neurosci. 2007;27(21):5796-804.

89. Kable JW, Glimcher PW. An "as soon as possible" effect in human intertemporal decision making: behavioral evidence and neural mechanisms. J Neurophysiol. 2010;103(5):2513-31.

90. O'Doherty JP. Reward representations and reward-related learning in the human brain: insights from neuroimaging. Curr Opin Neurobiol. 2004;14(6):769-76.

91. Bechara A, Damasio H, Tranel D, Anderson SW. Dissociation Of working memory from decision making within the human prefrontal cortex. J Neurosci. 1998;18(1):428-37.

92. Bechara A, Tranel D, Damasio H. Characterization of the decision-making deficit of patients with ventromedial prefrontal cortex lesions. Brain. 2000;123 ( Pt 11):2189-202.

93. Rolls ET, Hornak J, Wade D, McGrath J. Emotion-related learning in patients with social and emotional changes associated with frontal lobe damage. J Neurol Neurosurg Psychiatry. 1994;57(12):1518-24.

94. Goldstein RZ, Volkow ND. Drug addiction and its underlying neurobiological basis: neuroimaging evidence for the involvement of the frontal cortex. Am J Psychiatry. 2002;159(10):1642-52.

95. Madden GJ, Petry NM, Badger GJ, Bickel WK. Impulsive and self-control choices in opioid-dependent patients and non-drugusing control participants: drug and monetary rewards. Exp Clin Psychopharmacol. 1997;5(3):256-62.

96. Estes WK. Discriminative conditioning; effects of a Pavlovian conditioned stimulus upon a subsequently established operant response. J Exp Psychol. 1948;38(2):173-7.

97. Lovibond PF. Facilitation of instrumental behavior by a Pavlovian appetitive conditioned stimulus. J Exp Psychol Anim Behav Process. 1983;9(3):225-47.

98. Cooney NL, Litt MD, Morse PA, Bauer LO, Gaupp L. Alcohol cue reactivity, negative-mood reactivity, and relapse in treated alcoholic men. J Abnorm Psychol. 1997;106(2):243-50.

99. Garland EL, Franken IH, Howard MO. Cue-elicited heart rate variability and attentional bias predict alcohol relapse following treatment. Psychopharmacology (Berl). 2012;222(1):17-26.

100. Seo D, Lacadie CM, Tuit K, Hong KI, Constable RT, Sinha R. Disrupted ventromedial prefrontal function, alcohol craving, and subsequent relapse risk. JAMA Psychiatry. 2013;70(7):727-39.

101. Papachristou H, Nederkoorn C, Giesen JC, Jansen A. Cue reactivity during treatment, and not impulsivity, predicts an initial lapse after treatment in alcohol use disorders. Addict Behav. 2014;39(3):737-9.
102. Heinz A, Wrase J, Kahnt T, Beck A, Bromand Z, Grusser SM, et al. Brain activation elicited by affectively positive stimuli is associated with a lower risk of relapse in detoxified alcoholic subjects. Alcohol Clin Exp Res. 2007;31(7):1138-47.

103. Witteman J, Post H, Tarvainen M, de Bruijn A, Perna Ede S, Ramaekers JG, et al. Cue reactivity and its relation to craving and relapse in alcohol dependence: a combined laboratory and field study. Psychopharmacology (Berl). 2015;232(20):3685-96.

104. Koob GF, Volkow ND. Neurobiology of addiction: a neurocircuitry analysis. Lancet Psychiatry. 2016;3(8):760-73.

105. Haber SN, Knutson B. The reward circuit: linking primate anatomy and human imaging. Neuropsychopharmacology. 2010;35(1): 4-26.

106. Corbit LH, Janak PH, Balleine BW. General and outcome-specific forms of Pavlovian-instrumental transfer: the effect of shifts in motivational state and inactivation of the ventral tegmental area. Eur J Neurosci. 2007;26(11):3141-9.

107. Lex A, Hauber W. Dopamine D1 and D2 receptors in the nucleus accumbens core and shell mediate Pavlovian-instrumental transfer. Learn Mem. 2008;15(7):483-91.

108. Murschall A, Hauber W. Inactivation of the ventral tegmental area abolished the general excitatory influence of Pavlovian cues on instrumental performance. Learn Mem. 2006;13(2):123-6.

109. Schultz W. Behavioral dopamine signals. Trends Neurosci. 2007;30(5):203-10.

110. Schultz W, Dayan P, Montague PR. A neural substrate of prediction and reward. Science. 1997;275(5306):1593-9.

111. Hare TA, O'Doherty J, Camerer CF, Schultz W, Rangel A. Dissociating the role of the orbitofrontal cortex and the striatum in the computation of goal values and prediction errors. J Neurosci. 2008;28(22):5623-30.

112. Hare TA, Camerer CF, Rangel A. Self-control in decision-making involves modulation of the vmPFC valuation system. Science. 2009;324(5927):646-8.

113. Plassmann H, O'Doherty JP, Rangel A. Appetitive and aversive goal values are encoded in the medial orbitofrontal cortex at the time of decision making. J Neurosci. 2010;30(32):10799-808.

114. Plassmann H, O'Doherty J, Rangel A. Orbitofrontal cortex encodes willingness to pay in everyday economic transactions. $\mathrm{J}$ Neurosci. 2007;27(37):9984-8.

115. Hare TA, Malmaud J, Rangel A. Focusing attention on the health aspects of foods changes value signals in vmPFC and improves dietary choice. J Neurosci. 2011;31(30):11077-87.

116. O'Doherty J, Kringelbach ML, Rolls ET, Hornak J, Andrews C. Abstract reward and punishment representations in the human orbitofrontal cortex. Nat Neurosci. 2001;4(1):95-102.

117. Levy DJ, Glimcher PW. Comparing apples and oranges: using reward-specific and reward-general subjective value representation in the brain. J Neurosci. 2011;31(41):14693-707.

118. Montague PR, Berns GS. Neural economics and the biological substrates of valuation. Neuron. 2002;36(2):265-84.

119. Levy DJ, Glimcher PW. The root of all value: a neural common currency for choice. Current opinion in neurobiology. 2012;22(6): 1027-38.

120. Kable JW, Glimcher PW. The neural correlates of subjective value during intertemporal choice. Nat Neurosci. 2007;10(12):1625-33.

121. Buckner RL, Andrews-Hanna JR, Schacter DL. The brain's default network: anatomy, function, and relevance to disease. Ann $\mathrm{N}$ Y Acad Sci. 2008;1124:1-38.

122. Spreng RN, Stevens WD, Chamberlain JP, Gilmore AW, Schacter DL. Default network activity, coupled with the frontoparietal control network, supports goal-directed cognition. Neuroimage. 2010;53(1):303-17.

123. Pearson JM, Heilbronner SR, Barack DL, Hayden BY, Platt ML. Posterior cingulate cortex: adapting behavior to a changing world. Trends in cognitive sciences. 2011;15(4):143-51. 
124. Heilbronner SR, Hayden BY, Platt ML. Decision salience signals in posterior cingulate cortex. Front Neurosci. 2011;5:55.

125. Wagner AD, Shannon BJ, Kahn I, Buckner RL. Parietal lobe contributions to episodic memory retrieval. Trends in cognitive sciences. 2005;9(9):445-53.

126. Yeo BT, Krienen FM, Sepulcre J, Sabuncu MR, Lashkari D, Hollinshead M, et al. The organization of the human cerebral cortex estimated by intrinsic functional connectivity. J Neurophysiol. 2011;106(3):1125-65.

127. Ainslie G. Specious reward: a behavioral theory of impulsiveness and impulse control. Psychol Bull. 1975;82(4):463-96.

128. Audrain-McGovern J, Rodriguez D, Epstein LH, Cuevas J, Rodgers K, Wileyto EP. Does delay discounting play an etiological role in smoking or is it a consequence of smoking? Drug Alcohol Depend. 2009;103(3):99-106.

129. Fernie G, Peeters M, Gullo MJ, Christiansen P, Cole JC, Sumnall $\mathrm{H}$, et al. Multiple behavioural impulsivity tasks predict prospective alcohol involvement in adolescents. Addiction. 2013;108(11): 1916-23.

130. Kim-Spoon J, McCullough ME, Bickel WK, Farley JP, Longo GS. Longitudinal associations among religiousness, delay discounting, and substance use initiation in early adolescence. Journal of Research on Adolescence. 2015;25(1):36-43.

131. Stanger C, Ryan SR, Fu H, Landes RD, Jones BA, Bickel WK, et al. Delay discounting predicts adolescent substance abuse treatment outcome. Exp Clin Psychopharmacol. 2012;20(3):205-12.

132. Krishnan-Sarin S, Reynolds B, Duhig AM, Smith A, Liss T, McFetridge A, et al. Behavioral impulsivity predicts treatment outcome in a smoking cessation program for adolescent smokers. Drug Alcohol Depend. 2007;88(1):79-82.

133. Ersner-Hershfield H, Garton MT, Ballard K, Samanez-Larkin GR, Knutson B. Don't stop thinking about tomorrow: Individual differences in future self-continuity account for saving. Judgm Decis Mak. 2009;4(4):280-6.

134. Ersner-Hershfield H, Wimmer GE, Knutson B. Saving for the future self: neural measures of future self-continuity predict temporal discounting. Soc Cogn Affect Neurosci. 2009;4(1):85-92.

135. Hershfield HE, Goldstein DG, Sharpe WF, Fox J, Yeykelis L, Carstensen LL, et al. Increasing Saving Behavior through AgeProgressed Renderings of the Future Self. J Mark Res. 2011;48: S23-S37.

136. Schacter DL, Addis DR, Buckner RL. Remembering the past to imagine the future: the prospective brain. Nat Rev Neurosci. 2007;8(9):657-61.

137. Johnson SC, Baxter L C, Wilder LS, Pipe JG, Heiserman JE, Prigatano GP. Neural correlates of self-reflection. Brain. 2002;125(8):1808-14.

138. Northoff G, Heinzel A, De Greck M, Bermpohl F, Dobrowolny H, Panksepp JJN. Self-referential processing in our brain - a metaanalysis of imaging studies on the self. Neuroimage 2006;31(1): 440-57.

139. Murphy JG, Skidmore JR, Dennhardt AA, Martens MP, Borsari B, Barnett NP, et al. A behavioral economic supplement to brief motivational interventions for college drinking. Addict Res Theory. 2012;20(6):456-65.

140. Yurasek AM, Dennhardt AA, Murphy JG. A randomized controlled trial of a behavioral economic intervention for alcohol and marijuana use. Exp Clin Psychopharmacol. 2015;23(5):3328.

141. Rolls ET, McCabe C, Redoute J. Expected value, reward outcome, and temporal difference error representations in a probabilistic decision task. Cereb Cortex. 2008;18(3):652-63.

142. Kringelbach ML, O'Doherty J, Rolls ET, Andrews C. Activation of the human orbitofrontal cortex to a liquid food stimulus is correlated with its subjective pleasantness. Cereb Cortex. 2003;13(10):1064-71.
143. Kringelbach ML. The human orbitofrontal cortex: linking reward to hedonic experience. Nat Rev Neurosci. 2005;6(9):691-702.

144. Gilman JM, Hommer DW. Modulation of brain response to emotional images by alcohol cues in alcohol-dependent patients. Addict Biol. 2008;13(3-4):423-34.

145. Müller-Oehring EM, Jung YC, Sullivan EV, Hawkes WC, Pfefferbaum A, Schulte T. Midbrain-driven emotion and reward processing in alcoholism. Neuropsychopharmacology. 2013;38(10):1844-53.

146. Alba-Ferrara L, Müller-Oehring EM, Sullivan EV, Pfefferbaum A, Schulte T. Brain responses to emotional salience and reward in alcohol use disorder. Brain imaging and behavior. 2016;10(1): 136-46.

147. Boettiger CA, Mitchell JM, Tavares VC, Robertson M, Joslyn G, D'Esposito $\mathrm{M}$, et al. Immediate reward bias in humans: frontoparietal networks and a role for the catechol-O-methyltransferase 158(Val/Val) genotype. J Neurosci. 2007;27(52):14383-91.

148. Claus ED, Kiehl KA, Hutchison KE. Neural and behavioral mechanisms of impulsive choice in alcohol use disorder. Alcohol Clin Exp Res. 2011;35(7):1209-19.

149. Lim AC, Cservenka A, Ray LA. Effects of Alcohol Dependence Severity on Neural Correlates of Delay Discounting. Alcohol Alcohol. 2017;52(4):506-15.

150. Eklund A, Nichols TE, Knutsson H. Cluster failure: Why fMRI inferences for spatial extent have inflated false-positive rates. Proc Natl Acad Sci U S A. 2016;113(28):7900-5.

151. Lieberman MD, Cunningham WA. Type I and Type II error concerns in fMRI research: re-balancing the scale. Soc Cogn Affect Neurosci. 2009;4(4):423-8.

\section{REFERENCES FOR STUDIES USED IN META- ANALYSES}

Bach, P., G. Weil, E. Pompili, S. Hoffmann, D. Hermann, S. VollstadtKlein, K. Mann, U. Perez-Ramirez, D. Moratal, S. Canals, S. M. Dursun, A. J. Greenshaw, P. Kirsch, F. Kiefer and W. H. Sommer (2019). "Incubation of neural alcohol cue reactivity after withdrawal and its blockade by naltrexone." Addict Biol 25(1):e12717

Beck, A., P. Pelz, R. C. Lorenz, K. Charlet, O. Geisel, A. Heinz, T. Wustenberg and C. A. Muller (2018). "Effects of high-dose baclofen on cue reactivity in alcohol dependence: A randomized, placebocontrolled pharmaco-fMRI study." Eur Neuropsychopharmacol 28(11): 1206-1216.

Benoit, R. G., S. J. Gilbert and P. W. Burgess (2011). "A neural mechanism mediating the impact of episodic prospection on farsighted decisions." J Neurosci 31(18): 6771--6779.

Boettiger, C. A., E. A. Kelley, J. M. Mitchell, M. D'Esposito and H. L. Fields (2009). "Now or Later? An fMRI study of the effects of endogenous opioid blockade on a decision-making network." Pharmacol Biochem Behav 93(3): 291-299.

Hermann, D., M. N. Smolka, J. Wrase, S. Klein, J. Nikitopoulos, A. Georgi, D. F. Braus, H. Flor, K. Mann and A. Heinz (2006). "Blockade of cue-induced brain activation of abstinent alcoholics by a single administration of amisulpride as measured with fMRI." Alcohol Clin Exp Res 30(8): 1349-1354.

Herremans, S. C., P. Van Schuerbeek, R. De Raedt, F. Matthys, R. Buyl, J. De Mey and C. Baeken (2015). "The Impact of Accelerated Right Prefrontal High-Frequency Repetitive Transcranial Magnetic Stimulation (rTMS) on Cue-Reactivity: An fMRI Study on Craving in Recently Detoxified Alcohol-Dependent Patients." PLoS One 10(8):e0136182.

Holla, B., S. Karthik, J. Biswal, B. Viswanath, D. Jayarajan, R. D. Bharath, G. Venkatasubramanian and V. Benegal (2018). "Brain 
Functional Magnetic Resonance Imaging Cue-reactivity Can Predict Baclofen Response in Alcohol Use Disorders." Clin Psychopharmacol Neurosci 16(3): 290--301.

Hu, X., H. Kleinschmidt, J. A. Martin, Y. Han, M. Thelen, D. Meiberth, F. Jessen and B. Weber (2016). "A Reduction in Delay Discounting by Using Episodic Future Imagination and the Association with Episodic Memory Capacity." Front Hum Neurosci 10: 663.

Kiefer, F., M. Kirsch, P. Bach, S. Hoffmann, I. Reinhard, A. Jorde, C. von der Goltz, R. Spanagel, K. Mann, S. Loeber and S. Vollstadt-Klein (2015). "Effects of D-cycloserine on extinction of mesolimbic cue reactivity in alcoholism: a randomized placebo-controlled trial." Psychopharmacology (Berl) 232(13): 2353--2362.

Kirsch, M., I. Gruber, M. Ruf, F. Kiefer and P. Kirsch (2016). "Real-time functional magnetic resonance imaging neurofeedback can reduce striatal cue-reactivity to alcohol stimuli." Addict Biol 21(4): 982-992.

Lukas, S. E., S. B. Lowen, K. P. Lindsey, N. Conn, W. Tartarini, J. Rodolico, G. Mallya, C. Palmer and D. M. Penetar (2013). "Extended-release naltrexone (XR-NTX) attenuates brain responses to alcohol cues in alcohol-dependent volunteers: a bold FMRI study." Neuroimage 78: 176-185.

Luo, S., G. Ainslie and J. Monterosso (2014). "The behavioral and neural effect of emotional primes on intertemporal decisions." Soc Cogn Affect Neurosci 9(3): 283--291.

Peters, J. and C. Büchel (2010). "Episodic future thinking reduces reward delay discounting through an enhancement of prefrontalmediotemporal interactions." Neuron 66(1): 138--148.
Sasse, L. K., J. Peters and S. Brassen (2017). "Cognitive Control Modulates Effects of Episodic Simulation on Delay Discounting in Aging." Front Aging Neurosci 9: 58.

Sasse, L. K., J. Peters, C. Buchel and S. Brassen (2015). "Effects of prospective thinking on intertemporal choice: The role of familiarity." Hum Brain Mapp 36(10): 4210-4221.

Vollstädt-Klein, S., S. Loeber, M. Kirsch, P. Bach, A. Richter, M. Bühler, C. von der Goltz, D. Hermann, K. Mann and F. Kiefer (2011). "Effects of cue-exposure treatment on neural cue reactivity in alcohol dependence: a randomized trial." Biol Psychiatry 69(11): 1060-1066.

Wang, X. T., R. N. Reed, L. A. Baugh and K. A. Fercho (2018). "Resource forecasting: Differential effects of glucose taste and ingestion on delay discounting and self-control." Appetite 121: 101-110.

Wiehler, A., F. H. Petzschner, K. E. Stephan and J. Peters (2017). "Episodic Tags Enhance Striatal Valuation Signals during Temporal Discounting in pathological Gamblers." eNeuro 4(3).

Wiers, C. E., C. Stelzel, T. E. Gladwin, S. Q. Park, S. Pawelczack, C. K. Gawron, H. Stuke, A. Heinz, R. W. Wiers, M. Rinck, J. Lindenmeyer, H. Walter and F. Bermpohl (2015). "Effects of cognitive bias modification training on neural alcohol cue reactivity in alcohol dependence." Am J Psychiatry 172(4): 335--343

Publisher's Note Springer Nature remains neutral with regard to jurisdictional claims in published maps and institutional affiliations. 